\title{
EVIDÊNCIAS ADICIONAIS DA RELAÇÃO ENTRE EMPREENDEDORISMO E CRESCIMENTO ECONÔMICO
} ADDITIONAL EVIDENCE OF THE RELATIONSHIP BETWEEN ENTREPRENEURSHIP AND ECONOMIC

\author{
Silvio da Rosa Paula ${ }^{1}$ \\ Daniel de Abreu Pereira Uhr ${ }^{1}$ \\ Júlia Gallego Ziero Uhr ${ }^{1}$
}

Recebido em: 19/01/2017 Aceito em: 19/04/2017

daniel.uhr@gmail.com
Resumo: O objetivo deste artigo é investigar a influência do empreendedorismo no crescimento econômico. Utiliza-se três variáveis de empreendedorismo extraídas do Global Entrepreneurship Monitor juntamente com o índice de competitividade global elaborado pelo World Economic Forum, um indicador que captura o conjunto de instituições, políticas e fatores que definem o níveis atuais e médio prazo sustentáveis de prosperidade econômica. Para o modelo empírico utiliza-se o método de dados em painel com controle para efeitos fixos, para o período entre 2006 a 2014. Os resultados demonstram que o empreendedorismo é um fator importante para explicar o crescimento econômico, todavia seu impacto depende do estágio do desenvolvimento econômico dos países.

Palavras-chave: Empreendedorismo. Crescimento econômico. GEM. GCl.

Abstract: This study aims to investigate the impact of entrepreneurship on economic growth. Were used three variables of entrepreneurship from the Global Entrepreneurship Monitor in conjunction with the global competitiveness index elaborated by the World Economic Forum, an indicator that captures the Group of institutions, policies and factors that define the current and medium-term sustainable levels of economic prosperity. For the empirical model the panel data method with control for fixed effects is used for the period between 2006 and 2014. The results show that entrepreneurship is an important factor in explaining economic growth, but its impact depends on the stage of economic development in the countries.

Keywords: Entrepreneurship. Economic growth. GEM. GCI.

\footnotetext{
${ }^{1}$ Programa de Pós-Graduação em Organizações e Mercados - PPGOM/UFPEL - Pelotas - Rio Grande do Sul - Brasil.
} 


\section{INTRODUÇÂO}

O objetivo deste trabalho é testar se o empreendedorismo afeta o crescimento econômico dos países. Utilizamos indicadores do Global Entrepreneurship Monitor (GEM), e global competitiveness index $(\mathrm{GCl})$, elaborado pelo World Economic Forum (WEF) estes indicadores capturam os fatores institucionais e políticos e outros que influenciam a competitividade. O GCl é utilizado devido a importância das instituições que afetam a estrutura de incentivos influenciando a atividade empresarial fortalecendo o desenvolvimento econômico (ACEMOGLU e JOHNSON, 2005). Outras fontes secundárias também são utilizadas e os dados foram extraídos do Banco Mundial. Os dados compreendem o período entre 2006 e 2014 e a estimação empírica é executada através do método de mínimos quadrados empilhados com controles para efeitos fixos.

O trabalho foi dividido da seguinte forma, além desta introdução, a seção dois apresenta a revisão da literatura, nesta mesma seção apresentamos o Global Entrepreneurship Monitor e sua variável principal de trabalho, a taxa de empreendedores em estágio inicial (TEA), bem como o índice de competitividade global (GCl), e finalizando a seção expomos diversos estudos empíricos nacionais e internacionais que abordam a temática atividade empreendedora e crescimento econômico. A terceira seção é reservada para apresentação do método. Na quarta seção apresentamos os dados e as variáveis. Posteriormente, uma seção para apresentação dos resultados e outra para as considerações finais.

\section{A IMPORTÂNCIA DO EMPREENDEDORISMO}

A capacidade de empreender faz a diferença, o empreendedorismo é um fator fundamental para aperfeiçoar a capacidade de inovação, aumentar a produtividade e melhorar as estruturas de custo e desempenho. O empreendedor é o agente desenvolvedor de novos mercados, produtos, métodos de produção, gestão, na descoberta de novos insumos e no estabelecimento de novas empresas e até mesmo em novas formas organizacionais. Os Empresários e a equipes empreendedoras trazem à luz os recursos, tecnologias e oportunidades comerciais (HARPER, 2003).

$\mathrm{O}$ empreendedorismo vem sendo reconhecido como um determinante importante para o crescimento econômico, Pesquisas que avaliam o seu papel no crescimento econômico em países desenvolvidos, sugerem que um bom ambiente empresarial conduz ao progresso econômico sustentado, levando a expansão do mercado e inovação (STEL e THURIK, 2004; STAN e STEL, 2009; AFGHAH et al. 2014; MARQUES, 2014; MRABET e ELLOUZE, 2014; FONTENELE, 2010; ALMEIDA et al. 2014; ROCHA, 2014; BARTOLOMEU, 2015; OLIVEIRA e CARDOSO, 2015). Embora algumas pesquisas não tenham encontrado os mesmos resultados otimistas para os países com baixos níveis de desenvolvimento econômico (STEL e THURIK, 2004; STAN e STEL, 2009; MRABET e ELLOUZE, 2014; FONTENELE, 2010). Bosma e Levie, (2010) enfatizam que o empreendedorismo nos países menos desenvolvidos, não deve ser desencorajado, uma vez que negócios sustentáveis podem gerar melhores condições de vida e no longo prazo gerar benefícios para as próximas gerações.

Estudos do CEPE [ISSN 1982-6729]. Santa Cruz do Sul, n. 45, p. 127-142, jan./jun. 2017. https://online.unisc.br/seer/index.php/cepe/index 
Atualmente, o GEM é o maior estudo contínuo sobre a dinâmica empreendedora e teve seu início em 1999, com a participação de 10 países, e nesses 17 anos, tem mais de 100 países participantes do programa, que permanece crescendo. O programa da pesquisa é baseado em avaliações sobre o nível de atividade empreendedora nacional para todos os países participantes, envolve uma exploração do papel do empreendedorismo no crescimento econômico. O GEM tem três objetivos principais:

- Medir diferenças no nível de atividade empreendedora entre os países, identificando as diferentes características e fases do empreendedorismo.

- Identificar os fatores que determinam o nível de atividade empreendedora em cada pais.

- Identificar as políticas públicas que podem favorecer a atividade empreendedora local.

O GEM faz análise do empreendedorismo de acordo com os estágios do processo empreendedor, que tem seu início com o potencial empreendedor, passando pelos estágios iniciais de desenvolvimento, criação do empreendimento até ser considerado estabelecido, como pode ser visto na ilustração abaixo:

Figura 1 - Processo empreendedor segundo definições do GEM

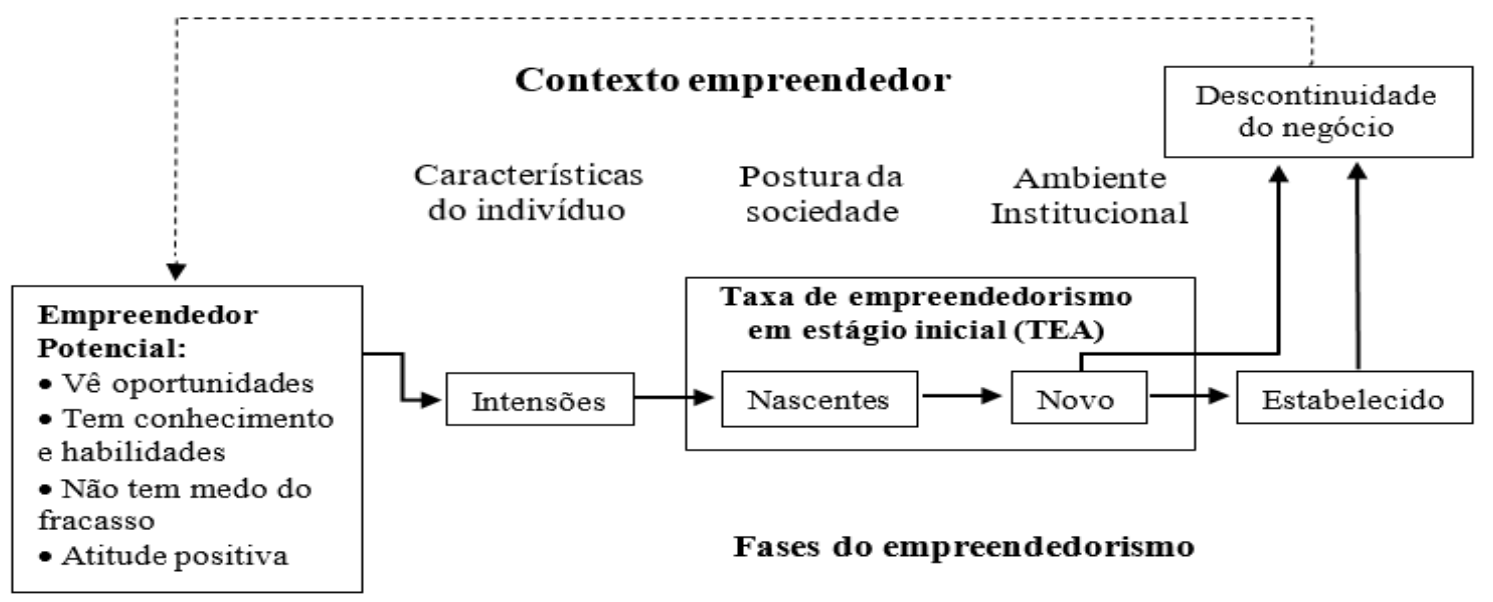

Fonte: GEM Global Entrepreneurship Monitor 2011.

O principal indicador do GEM é a Total early-stage Entrepreneurial Activity (TEA), a Taxa de empreendedorismo em estágio inicial definida como a proporção de pessoas na faixa etária entre 18 e 64 anos envolvidas em atividades empreendedoras na condição de empreendedores de negócios nascentes ou empreendedores à frente de negócios novos, com menos de três anos e meio de existência.

O GEM diferencia os agentes empreendedores em função da sua motivação para empreender, por oportunidade ou necessidade. A motivação para iniciar uma atividade empreendedora é um dos focos principais do programa GEM. Para o GEM o impacto das diferentes características da atividade empreendedora depende do estágio de desenvolvimento econômico de cada país. Partindo dessa perspectiva o GEM assume a classificação dos estágios de desenvolvimento econômico derivada do GCR Global Competitiveness Report.

Estudos do CEPE [ISSN 1982-6729]. Santa Cruz do Sul, n. 45, p. 127-142, jan./jun. 2017. https://online.unisc.br/seer/index.php/cepe/index 
O Relatório de Competitividade Global (GCR) é um relatório anual publicado desde 2004 pelo Fórum Econômico Mundial (WEF), o GCR classifica os países com base no global competitiveness index $(\mathrm{GCl}$ - índice de competitividade Global). O $\mathrm{GCl}$ é uma ferramenta completa que mede os fundamentos microeconômicos e macroeconômicos da competitividade. Foi desenvolvida por Xavier Sala-i-Martin e Elsa V. Artadi, em colaboração com o WEF, baseado na ideia original de Klaus Schwab (1979). O projeto define a competitividade como o conjunto de instituições, políticas e fatores que determinam o nível de produtividade de uma economia, que por sua vez define o nível de prosperidade que pode ser atingido (SALA-I-MARTÍN et al., 2015; SALA-I-MARTíN et al., 2016).

O GCl combina 114 indicadores em 12 pilares. Todos pilares são importantes em certa medida para todos os países, porém cada pilar afeta de maneira diferente cada economia. O GCl então considera um peso relativo maior para os pilares que são mais relevantes para cada economia dada sua fase particular de desenvolvimento como pode ser visto na Tabela 1 abaixo.

Tabela 1 - Pesos e limites de renda para os estágio do desenvolvimento

ESTÁGIOS DO DESENVOLVIMENTO

\begin{tabular}{|c|c|c|c|c|c|}
\hline & $\begin{array}{l}\text { Estágio 1: } \\
\text { orientados } \\
\text { por fatores }\end{array}$ & $\begin{array}{c}\text { Transição } \\
\qquad 1 \rightarrow 2\end{array}$ & $\begin{array}{l}\text { Estágio 2: } \\
\text { orientados } \\
\text { pela } \\
\text { eficiência }\end{array}$ & $\begin{array}{l}\text { Transição } \\
\qquad 2 \rightarrow 3\end{array}$ & $\begin{array}{c}\text { Estágio 3: } \\
\text { orientados } \\
\text { pela } \\
\text { inovação }\end{array}$ \\
\hline $\begin{array}{l}\text { GDP per capita (US\$) } \\
\text { thresholds* }\end{array}$ & $<2,000$ & $\begin{array}{l}2,000- \\
2,999\end{array}$ & $\begin{array}{l}3,000- \\
8,999\end{array}$ & $\begin{array}{l}9,000- \\
1,700\end{array}$ & $>17,000$ \\
\hline Requisitos básicos & $60 \%$ & $40-60 \%$ & $40 \%$ & $20-40 \%$ & $20 \%$ \\
\hline Potenciadores de eficiência & $35 \%$ & $35-50 \%$ & $50 \%$ & $50 \%$ & $50 \%$ \\
\hline $\begin{array}{l}\text { Fatores de inovação e } \\
\text { sofisticação }\end{array}$ & $5 \%$ & $5-10 \%$ & $10 \%$ & $10-30 \%$ & $30 \%$ \\
\hline
\end{tabular}

- Para economias com alta dependência dos recursos minerais, o GDP per capita não é a único critério para a determinação do estágio de desenvolvimento².

Fonte: World Economic Forum; IMF World Economic Outlook Database April 2014.

Para implementar este conceito, os pilares são organizados em três subíndices: Requerimentos básicos; Potenciadores de eficiência e fatores de inovação e sofisticação como pode ser visto na Tabela 2.

\footnotetext{
${ }^{2}$ Ver mais em the Global Competitiveness Report 2014-2015.
}

Estudos do CEPE [ISSN 1982-6729]. Santa Cruz do Sul, n. 45, p. 127-142, jan./jun. 2017. https://online.unisc.br/seer/index.php/cepe/index 
Tabela 2 - Os 12 pilares do índice global de competitividade

\section{Economias}

\section{Requerimentos básicos}

Pilar 1. Instituições

Pilar 2. Infraestrutura

Pilar 3. Ambiente macroeconômico

Orientados por fatores

Pilar 4. Saúde e educação primária

\section{Potenciadores de eficiência}

Pilar 5. Educação superior e treinamento

Pilar 6. Eficiencia no mercado de bens

Pilar 7. Eficiencia do mercado de trabalho

Orientados pela eficiência

Pilar 8. Desenvolvimento do mercado financeiro

Pilar 9. Prontidão tecnológica

Pilar 10. Tamanho do mercado

\section{Fatores de inovação e sofisticação}

Pilar 11. Sofisticação dos negócios

Orientados pela inovação

Pilar 12. Inovação

Fonte: The Global Competitiveness Report 2015-2016.

O GCl defende que na primeira fase de desenvolvimento as economias são impulsionadas por fatores, a qual se caracteriza pela mão-de-obra pouco qualificada e exploração dos recursos naturais. As empresas vendem produtos de base ou commodities e a baixa produtividade é refletida nos baixos salários. A manutenção da competitividade nesta fase de desenvolvimento depende principalmente do bom funcionamento das instituições públicas e privadas (pilar 1), infraestrutura bem desenvolvida (pilar 2). Ambiente macroeconômico estável (pilar 3) e força de trabalho saudável com no mínimo educação primária (pilar 4). A medida que as economias se tornam mais competitivas, a produtividade aumenta e os salários sobem com o avanço do desenvolvimento. Esses países então transitam do estágio de economias impulsionadas por fatores para econômicas impulsionadas pela eficiência. Nesse estágio novos processos de produção mais eficientes são desenvolvidos melhorando a qualidade dos produtos uma vez que os salários subiram e não é possível aumentar os preços. Nesse ponto a competitividade é cada vez mais impulsionada pela educação superior e treinamento (pilar 5), mercados eficientes (pilar 6), eficiência do mercado de trabalho (pilar 7) bom funcionamento do mercado financeiro (pilar 8) capacidade de absorção das tecnologias existentes (pilar 9) e um grande mercado nacional e estrangeiro (pilar 10). Por fim, com as economias transitando para o estágio impulsionados pela inovação os salários refletem o quanto as empresas são capazes de competir com os novos produtos criados. Nesta fase, as empresas devem competir através da produção de mercadorias inovadoras, utilizando os mais sofisticados processos de produção (pilar 11) e inovando (pilar 12) (SALA-I-MARTíN et al., 2015; SALA-I-MARTíN et al., 2016). 


\subsection{Empreendedorismo, instituições e crescimento econômico}

Embora o empreendedorismo seja amplamente reconhecido como fator importante para moldar a ambiente econômico, a relação entre empreendedorismo e crescimento econômico está longe de ser compreendida por completo. Segundo o relatório do GEM (2007) conforme as evidências científicas para este relacionamento foram surgindo, as instituições foram se tornando cada vez mais importantes para compreender essa relação. Sendo assim faz-se necessário mais que medidas quantitativas de empreendedorismo, mas também medidas qualitativas institucionais para inferir sobre o impacto do empreendedorismo no crescimento econômico (BOSMA et al, 2008).

Bosma et al (2008) revelam a existência de um padrão especifico na associação entre o TEA e o GDP per capita, evidenciando que taxas de TEA tendem a ser maiores em economias menos desenvolvidas, e em economias orientadas pela inovação o padrão tende a ser o oposto como pode ser visto no gráfico abaixo:

Figura 2 - TEA de 2014 segundo as fases do desenvolvimento econômico

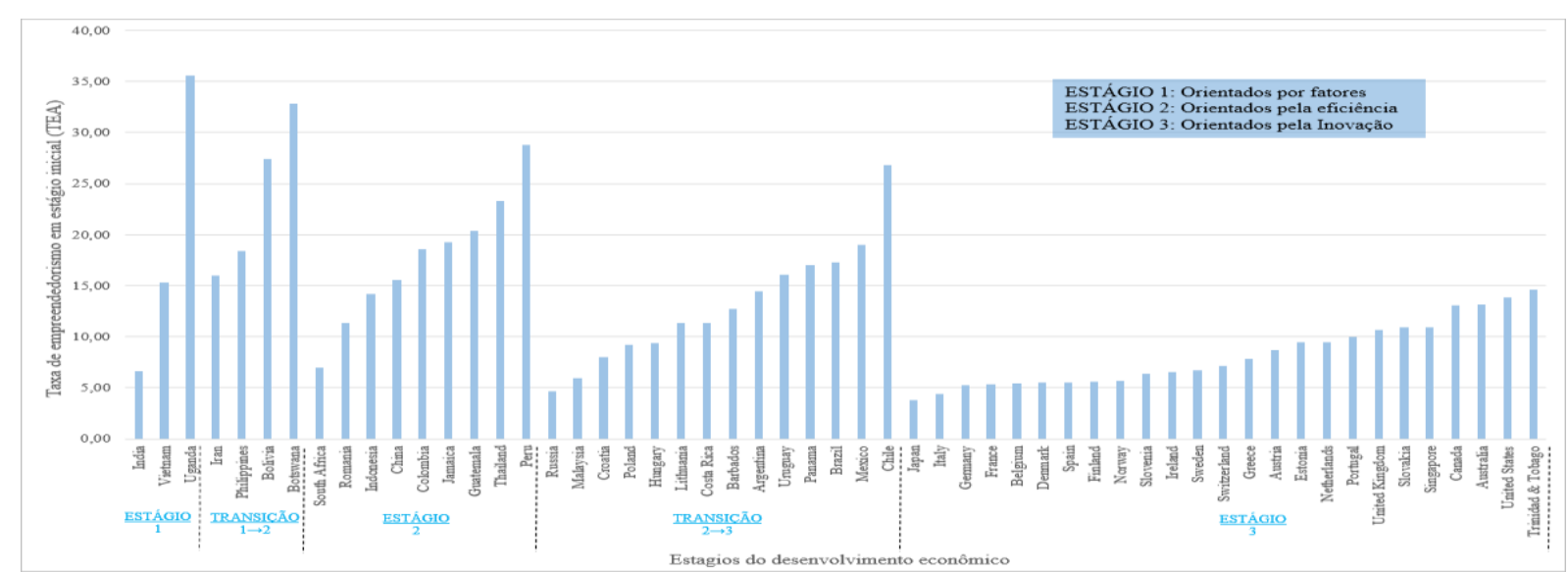

Fonte: Elaborado pelo autor baseado no GCR The Global Competitiveness Report.

Relatórios anteriores do GEM demonstraram uma relação em forma de $U$ entre os níveis de GDP per capita e o TEA, e essa relação tem se demonstrado constante ao longo dos anos.

Estudos do CEPE [ISSN 1982-6729]. Santa Cruz do Sul, n. 45, p. 127-142, jan./jun. 2017. https://online.unisc.br/seer/index.php/cepe/index 
Figura 3 - Correlação entre TEA e GDP per capita 2014.

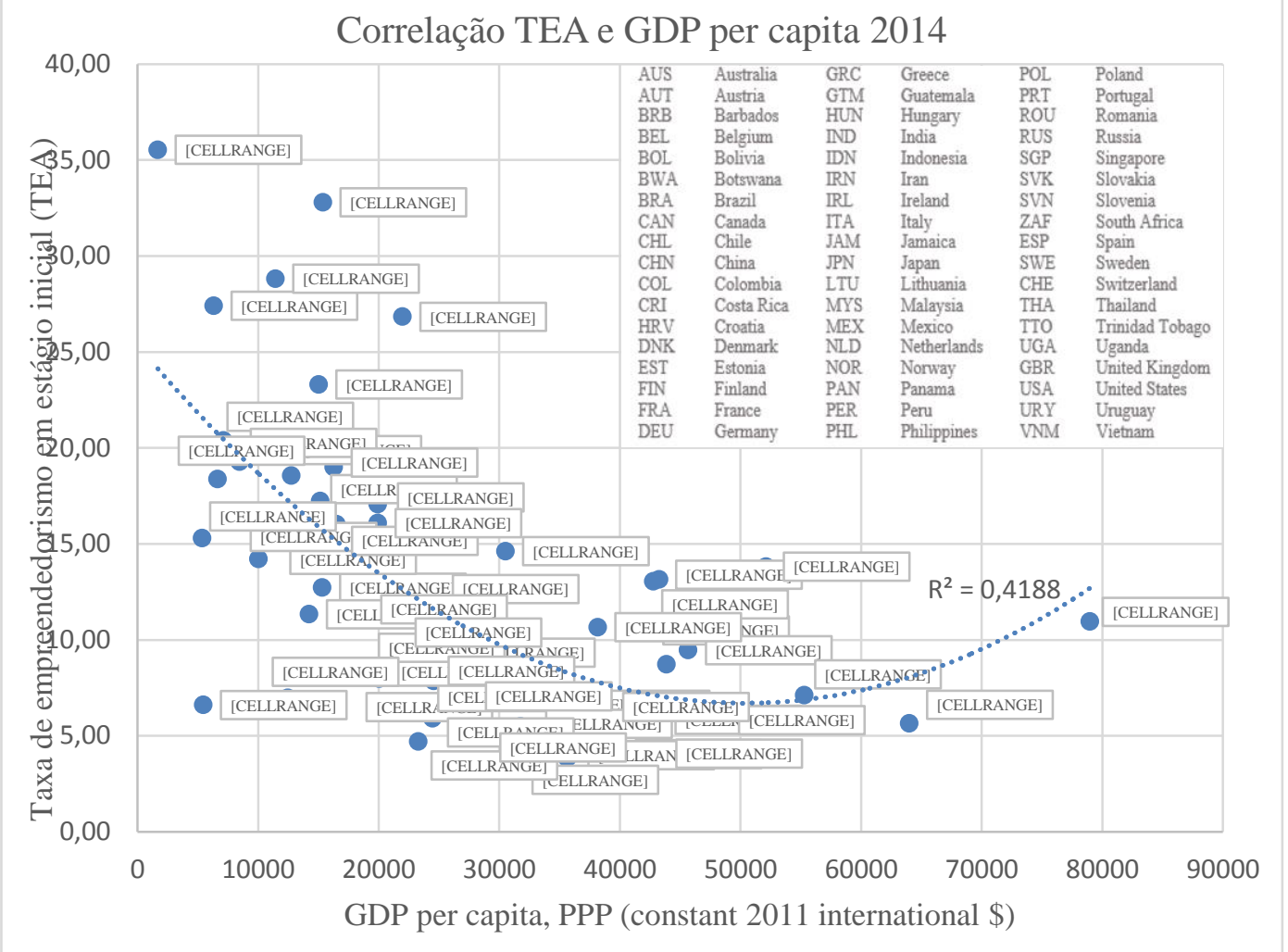

Fonte: Elaborado pelo autor baseado nos relatórios do GEM.

A correlação em forma de U, é explicado por ACS et al. (2004) e Bosma et al. (2008) da seguinte maneira: economias orientadas por fatores, apresentam altas taxas de empreendedorismo por necessidade, formada por empreendedores com baixos níveis de educação formal que tendem a utilizar menos tecnologias sofisticas oferecendo basicamente produtos de origem extrativistas. Conforme grandes empresas se estabelecem fornecendo uma opção de emprego estável o número de empreendedores por necessidade cai, reduzindo a taxa TEA o que deve ser entendido como um bom sinal especialmente se acompanhada pela estabilidade macroeconômica e política. Nas economias orientadas pela eficiência à medida que a renda per capita cresce, e o setor industrial se desenvolve, as instituições começam a surgir para apoiar novas indústrias.

Com a difusão de novas tecnologias e economias de escala a produtividade aumenta o que permite absorver as crescentes demandas do mercado. $\mathrm{O}$ aumento da produtividade econômica contribui para a formação de capital financeiro abrindo novas oportunidades em cadeias de suprimentos industriais para atender os novos setores fazendo cair gradualmente 0 empreendedorismo por orientando pela necessidade e dando lugar a um setor emergente de fabricação em pequena escala.

Por fim, nas economias orientadas pela inovação, o empreendedorismo volta a crescer em importância, na medida que o ambiente econômico permite a exploração de novas oportunidades associadas ao aumento das pesquisas e instituições geradoras de conhecimento, desenvolvendo uma atividade empresarial baseada na oportunidade na busca pela inovação, desafiando os operadores já estabelecidos "agentes de destruição criativa".

Estudos do CEPE [ISSN 1982-6729]. Santa Cruz do Sul, n. 45, p. 127-142, jan./jun. 2017. https://online.unisc.br/seer/index.php/cepe/index 


\subsection{Literatura empírica}

O trabalho de Stan e Stel (2009) investigam o efeito do empreendedorismo sobre o crescimento econômico para 36 países participantes do GEM em 2002, um elemento importante deste trabalho é a comparação dos efeitos em países de alta renda, transição e de baixa renda. Os dados foram extraídos do GEM, FMI e WEF. Os resultados indicam que a presença de empresários por oportunidade parece ser mais importante para alcançar o crescimento econômico do que empreendedorismo geral. Por fim as análises empíricas sugerem que empreendedorismo não tem um efeito sobre o crescimento econômico em países de baixa renda, em contraste aos países de transição e de alta renda onde tanto o empreendedorismo orientado para o crescimento e o empreendedorismo em geral parece contribuir fortemente para o crescimento macroeconômico.

A pesquisa de Smith (2010) investiga a posição do empreendedorismo no contexto do crescimento econômico através de um conjunto de dados transversais para 77 países, para o ano de 2005. Todos os dados foram extraídos do Banco Mundial. Seis diferentes fatores econômicos são examinados na análise estatística (crescimento econômico; empreendedorismo; trabalho; capital; conhecimento e políticas governamentais pró-mercado). Os resultados confirmam que o empreendedorismo tem um impacto significativo sobre o crescimento econômico, e que a presença do empreendedorismo em uma sociedade não pode ser completamente explicada pelos fatores neoclássicos tradicionais que influenciam o crescimento económico, portanto, o empreendedorismo deve ser incluído como um fator independente no modelo neoclássico de crescimento económico.

Afghah et al. (2014) tem como objetivo verificar o efeito do empreendedorismo no crescimento económico a partir da visão de Schumpeteriana, para 50 países no período entre 2004 e 2012. Os dados foram extraídos do GEM e FMI. Usando a abordagem de dados em painel desequilibrado com efeito fixo. Os resultados obtidos indicam que o empreendedorismo tem efeito positivo e significativo no crescimento econômico, onde o aumento de uma unidade percentual no variável empreendedorismo irá resultar no acréscimo de $0,074 \%$ no crescimento econômico.

Marques (2014) em seu trabalho tem como objetivo de avaliar a contribuição do empreendedorismo, para o crescimento económico dos países da Organisation for Economic Cooperation and Development (OCDE), partindo de uma função de produção agregada de elasticidade de substituição constantes (CES), em uma abordagem de contabilidade do crescimento, para o período entre 2001 e 2007. Os dados foram extraídos do GEM e da Annual Macro-Economic database of the European Commission's (AMECO). Os resultados obtidos sugerem que o empreendedorismo contribuiu em média cerva de 0,3 pontos percentuais da taxa de crescimento do produto real, através do crescimento da eficiência do trabalho, esse resultado base, sugere que existe uma relação positiva entre o nível de empreendedorismo e sua contribuição absoluta para a taxa de crescimento do produto, mas também que essa relação torna-se ambígua ao considerar as contribuições relativas, sobretudo no conjunto dos países onde este fica abaixo de $10 \%$, ou $7 \%$, estes resultados sugerem que cada economia obtém diferentes benefícios de um mesmo nível de empreendedorismo, que poderão depender de outros fatores, como a frequência de criação de novos conhecimentos, que gerem novas oportunidades para os empreendedores.

Estudos do CEPE [ISSN 1982-6729]. Santa Cruz do Sul, n. 45, p. 127-142, jan./jun. 2017. https://online.unisc.br/seer/index.php/cepe/index 
Almeida et al. (2014) tem o objetivo de identificar os efeitos do empreendedorismo sobre desempenho econômico dos estados brasileiros e verificar se tais efeitos se diferem entre os 26 estados do Brasil mais o Distrito Federal para o período de 2001 a 2011. Os dados foram coletados do Instituto Brasileiro de Geografia e Estatística (IBGE), Ministério do Desenvolvimento, Indústria e Comércio Exterior (MDIC), Pesquisa Nacional por Amostra de Domicílios (PNAD), Ministério da Fazenda, Tesouro Nacional. A análise dos resultados obtidos enfatiza o relevante papel desempenhado da atividade empreendedora sobre o PIB mesmo para os estados mais pobres, seja por inovação ou por promoção de novos negócios, os efeitos das atividades empreendedoras sobre o crescimento econômico dos estados, no geral, homogêneos e positivos, favorecendo assim o crescimento econômico.

Rocha (2014) aborda a importância do empreendedorismo por necessidade e oportunidade para o crescimento e desenvolvimento econômico. Os resultados empíricos indicam que a razão entre empreendedorismo por oportunidade e necessidade podem explicar cerca de $24 \%$ da variação total do (IDH), e que a variação de cada unidade positiva da (RON) poderá aumentar em 0,015 o (IDH), confirmando a hipótese levantada de que uma razão maior entre empreendedorismo por oportunidade e necessidade influencia positivamente o IDH dos países. Por fim segundo a pesquisa o empreendedorismo por oportunidade atua positivamente no desenvolvimento econômico dos países. No entanto o autor salvaguarda a respeito do empreendedorismo por necessidade, que apesar de em vários estudos não apontar relação significativa ou até mesmo negativa com o crescimento econômico, tem seu papel importante como fonte geradora de emprego e auto emprego.

Bartolomeu (2015) seu estudo faz uma análise do crescimento económico e a sua correlação com o empreendedorismo, globalização, investimento direto estrangeiro e o comércio internacional, comtemplando 92 países no período de 2000 a 2012, bem como os determinantes do crescimento económico. Os resultados obtidos concluem que: o GDP defasado tem um impacto positivo, o que significa que o PIB real apresenta um impacto positivo no longo prazo e a globalização revela indícios de que não promove o crescimento económico. No entanto a atividade empreendedora apresenta resultados ambíguos.

Oliveira e Cardoso (2015) têm como objetivo analisar a influência do nível de atividade empreendedora e o grau de empreendedorismo por oportunidade na competitividade e no desenvolvimento social e econômico dos países. Os resultados mostram que um aumento em um ponto percentual taxa de empreendedorismo diminui a renda per capita em -1.054 a um nível de significância de 0,01\%, confirmando a primeira hipótese levantada de que há uma relação negativa entre empreendedorismo e o desenvolvimento econômico, social e competitividade de um país. Por outro lado, verifica-se uma relação positiva, com significância estatística de 0,01\% entre o nível de empreendedorismo por oportunidade e a renda per capita, corroborando com a hipótese 2 de que há uma relação positiva entre empreendedorismo por oportunidade e desenvolvimento econômico, social e competitividade de um país.

Estudos do CEPE [ISSN 1982-6729]. Santa Cruz do Sul, n. 45, p. 127-142, jan./jun. 2017. https://online.unisc.br/seer/index.php/cepe/index 


\section{MÉTODO}

Com objetivo de avaliar o impacto da atividade empreendedora no crescimento económico dos 70 países selecionados para período entre 2006 e 2014, utilizamos o Método dos mínimos quadrados empilhados, com controle de efeitos fixos para cada ano e, também, para cada estágio do desenvolvimento segundo os relatórios do GCR. Segundo Baltagi (2008), uma regressão de dados em painel difere de uma série temporal ou cross-section na medida que tem duplo subscrito em suas variáveis, ou seja:

$$
Y_{i t}=\alpha+X_{i t}^{\prime} \beta+\theta_{i}+\varphi_{t}+\mu_{i t} \quad i=1, \ldots, \mathrm{N} ; \quad t=1, \ldots, \mathrm{T}
$$

Onde: $i$ denota os países $i=1, \ldots, 70$; e $t$ denota o tempo $t=2006, \ldots, 2014$. O subscrito $i$ portanto denota a dimensão da seção transversal considerando que $t$ denota a dimensão das series temporais. $\mathrm{O} \alpha$ é um escalar, $\beta$ é um vetor $K \times 1$, e $X_{i t}$ é a matriz de variáveis explicativas. Já os efeitos fixos de estágio e de tempo são $\theta_{i}$ e $\varphi_{t}$, respectivamente e, por fim, $\mu_{i t}$ é o termo de erro.

\section{DADOS}

Os dados utilizados foram extraídos do Global Entrepreneurship Monitor; World Economic Forum e World Bank Group. Utilizamos todos os dados disponíveis, isto é, a amostra é composta por 70 países conforme a classificação no Global Competitiveness Report 2014-2015 e do GEM, para o período de 2006 a 2014

As variáveis utilizadas são: GDP per capita: variável dependente, PIB per capita baseado na paridade de poder de compra (PPP). PPP GDP é produto interno bruto, convertido em dólares internacionais usando taxas de paridade de poder de compra. $\mathbf{G C l}$ : Indicador de competitividade global para o período de 2006 a 2014. TEA: total early-stage Entrepreneurial Activity. (Taxa total de empreendedorismo em estágio inicial) é definida como a percentagem de população em idade ativa envolvidas em atividades empreendedoras na condição de empreendedores de negócios nascentes ou empreendedores à frente de negócios novos, com idade inferior a 42 meses de existência. TEA-N: Necessity-Driven Entrepreneurial Activity. Taxa de empreendedores por necessidade é definida como a percentagem de pessoas envolvidas no TEA, por não terem outras opções de trabalho. TEA-O: Improvement-Driven Opportunity Entrepreneurial Activity. A taxa de empreendedores por oportunidade é definida como a percentagem de pessoas envolvidas no TEA que afirmam ser impulsionados pelas oportunidades, e que indicam que sua principal motivação é a independência ou retornos maiores em seus rendimentos. E, além destas, foram utilizadas variáveis binárias (controles para efeitos fixos) para cada fase do desenvolvimento conforme a classificação do Global Competitiveness Report e para cada ano.

Estudos do CEPE [ISSN 1982-6729]. Santa Cruz do Sul, n. 45, p. 127-142, jan./jun. 2017. https://online.unisc.br/seer/index.php/cepe/index 
Tabela 3 - Variáveis utilizadas na pesquisa e suas respectivas fontes

\begin{tabular}{llcl}
\hline Variável & $\begin{array}{l}\text { Sinal } \\
\text { esperado }\end{array}$ & Descrição & Fonte \\
\hline GDPpp & $(+)$ & GDP per capita & WBG \\
GCl & $(+)$ & Indicador de competitividade global & WEF \\
TEA & $(+/-)$ & Taxa de empreendedorismo em estágio inicial & GEM \\
TEA-N & $(-)$ & Taxa de empreendedores por Necessidade & GEM \\
TEA-O & $(+)$ & Taxa de empreendedores por Oportunidade & GEM \\
\hline Fonte: Elaborada pelo autor. & &
\end{tabular}

A Tabela 4 e a Tabela 5 apresentam as estatísticas descritivas e a matriz de correlação das variáveis utilizadas, para a amostra de países no período entre 2006 a 2014.

Tabela 4 - Estatísticas descritivas das variáveis utilizadas

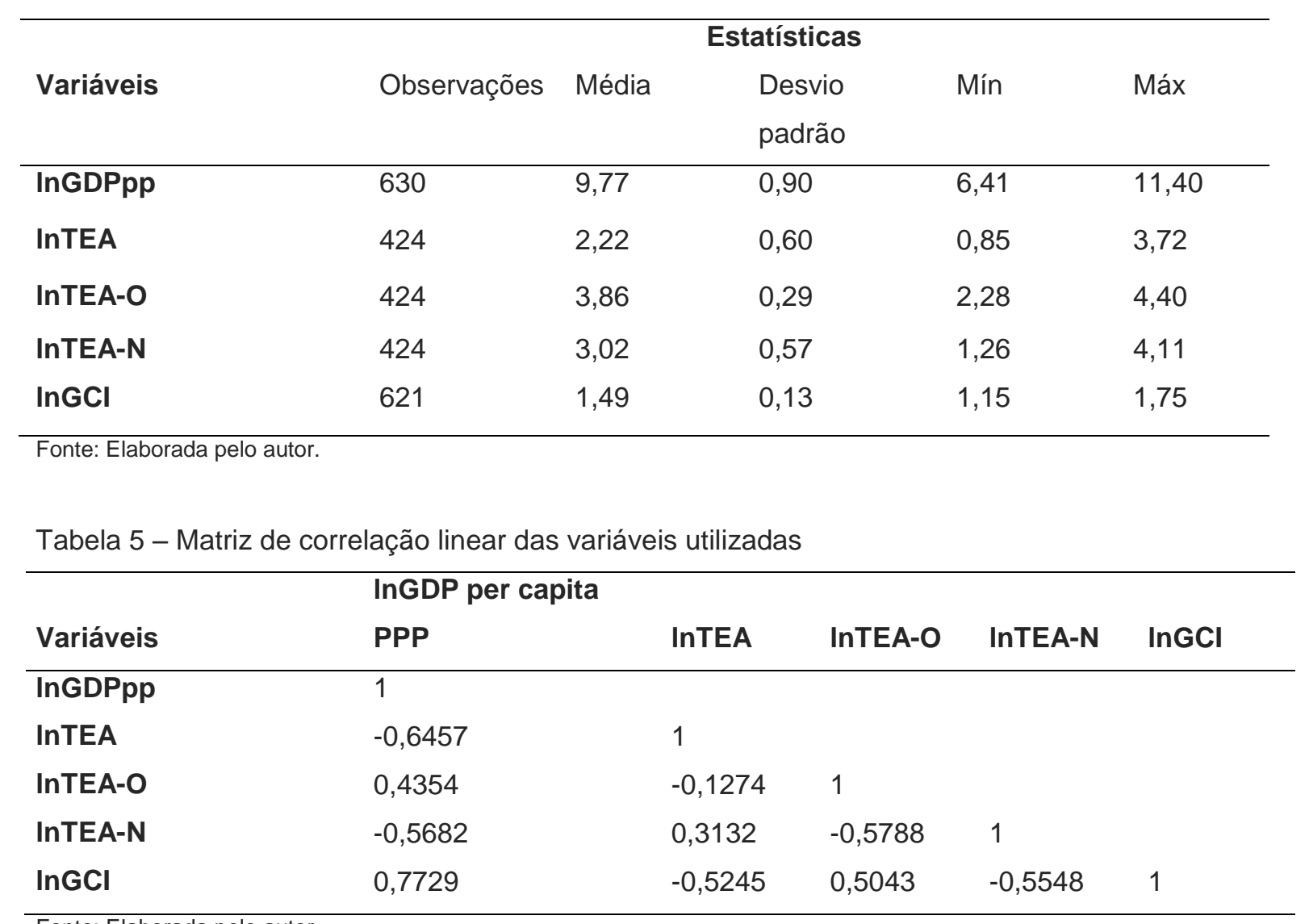

Fonte: Elaborada pelo autor.

\section{RESULTADOS}

A Tabela 6 apresenta os resultados obtidos para os dados modelados por mínimos quadrados ordinários em painel empilhados com estimação por efeitos fixos. Na primeira coluna são apresentadas variáveis, na segunda coluna (Todos os países) são expostos os resultados estimados considerando todos os países. Nas colunas seguintes três, quatro e cinco são apresentados os

Estudos do CEPE [ISSN 1982-6729]. Santa Cruz do Sul, n. 45, p. 127-142, jan./jun. 2017. https://online.unisc.br/seer/index.php/cepe/index 
resultados para os países agrupados conforme seu estágio de desenvolvimento. Estágio 1 são aqueles orientados por fatores; O estágio 2 são aqueles orientados pela eficiência; já o estágio 3 são aqueles orientados pela inovação.

Tabela 6 - Resultados do modelo econométrico

\begin{tabular}{lllll}
\hline Modelo & Todos os países & Estágio 1 & Estágio 2 & Estágio 3 \\
Metodologia: & OLS-FE & OLS-FE & OLS-FE & OLS-FE \\
\hline InTEA & $-0,2725^{* * *}$ & $-0,4946^{* *}$ & $-0,4030^{* * *}$ & $0,1042^{* * *}$ \\
InTEA-O & $0,2185^{* *}$ & $1,8821^{* *}$ & $0,2673^{*}$ & $-0,0765$ \\
InTEA-N & $-0,1232^{* *}$ & 0,5783 & $-0,1713^{*}$ & $-0,1498^{* * *}$ \\
InGCI & $1,4386^{* * *}$ & $4,3449^{* *}$ & $1,0686^{*}$ & $1,5858^{* * *}$ \\
Estagio2 & $0,6776^{* * *}$ & - & - & - \\
Estagio3 & $1,1220^{* * *}$ & - & - & - \\
Constante & $6,9964^{* * *}$ & $-5,0376$ & $8,5367^{* * *}$ & $8,4849^{* * *}$ \\
\hline E. Fixo Tempo & SIM & SIM & SIM & SIM \\
R-quadrado & $0,7927^{* * *}$ & $0,4971^{* * *}$ & $0,4722^{* * *}$ & $0,6197^{* * *}$ \\
Observações & 421 & 47 & 179 & 195 \\
VIF mean & 2.49 & 2.94 & 1.91 & 1.83 \\
\hline Fon & 4.94 & &
\end{tabular}

Fonte: elaborado pelo autor a partir dos resultados obtidos do software Stata 13.

${ }^{*} p<0.10,{ }^{* *} p<0.05,{ }^{* * *} p<0.01$. Todas as regressões são robustas a heterocedasticidade.

As estimações do modelo contendo todos os países em um único grupo, revelam que a taxa de empreendedorismo em estágio inicial TEA denota estar em conformidade com a teoria anteriormente exposta. Apresentando um efeito negativo e significativo sobre o PIB per capita, corroborando com os resultados encontrados por (STEL e THURIK, 2004; WONG, HO e AUTIO, 2005; ACS, 2006; FONTENELE, 2010; OLIVEIRA e CARDOSO, 2015). Nota-se que um aumento em 1 ponto percentual taxa TEA diminui a renda per capita em $-0,27 \%$ a um nível de significância de $1 \%$. Por sua vez, verifica-se uma relação positiva, com significância estatística $(p<0.05)$ entre o nível de empreendedorismo por oportunidade TEA-O e a renda per capita. No qual um aumento em 1 ponto percentual na taxa (TEA-O) eleva a renda em aproximadamente $0,21 \%$. Os resultados corroboram com evidências de estudos anteriores (STAN e STEL, 2009; ROCHA, 2014).

A variável TEA-N revelou influência negativa sobre a variável dependente, confirmando a expectativa de que o empreendedorismo por necessidade impacta de forma negativa no PIB per capita. Nesse caso um aumento em 1 unidade percentual de empreendedorismo por necessidade reduz a renda per capita em $-0,49 \%$, a um nível de significância de $5 \%$. Corroborando com resultados anteriormente encontrados por (STAN e STEL, 2009; ROCHA, 2014). Por outro lado, verifica-se uma relação positiva, com significância estatística 1\% entre o índice de competitividade global (GCl) e a renda per capita. Onde um aumento em 1 ponto percentual da taxa de $\mathrm{GCl}$ eleva a renda per capita

Estudos do CEPE [ISSN 1982-6729]. Santa Cruz do Sul, n. 45, p. 127-142, jan./jun. 2017. https://online.unisc.br/seer/index.php/cepe/index 
em aproximadamente $1,43 \%$. Os resultados corroboram com as evidências encontradas por estudos anteriores de Fontenele 2011 e de Rocha 2014.

Além disso, observa-se que o $\mathrm{R}^{2}$ é igual a 0,79 , indicando que o modelo explica em $79 \%$ a renda per capita dos países analisados. Os resultados obtidos demonstram que ao estimar um modelo contendo vários países em um único grupo desconsiderando suas características de desenvolvimento não possível verificar o caráter em forma de $U$ da correlação entre a taxa de empreendedorismo em estágio inicial TEA e PIB apresentado na Figura 3. Consequentemente a taxa TEA apresenta um sinal predominantemente negativo, influenciando de maneira negativa o PIB per capita ${ }^{3}$.

As estimações dos modelos com os países agrupados conforme a fase do desenvolvimento. Revelam que para os países que se encontram nas duas primeiras fases "países orientados por fatores e países orientados pela eficiência" a taxa TEA exerce uma influência negativa na Renda per capita na ordem de $-0,49 \%$ e - $-4,40 \%$ a um nível de significância de 5\% e 1\% respectivamente. Em contrapartida, para os países que se encontram na terceira fase do desenvolvimento "orientados pela eficiência" nota-se que aumento em 1 ponto percentual taxa do TEA aumenta a renda per capita em 0,10 a um nível de significância 1\% corroborando com (STEL e THURIK, 2004; AUDRETSCH et al., 2006; STAN e STEL, 2009; FONTENELE, 2011).

A variável empreendedorismo por oportunidade TEA-O, influência de forma positiva a renda per capita dos países que estão nos dois primeiros estágios do desenvolvimento. No estágio 1 notase que o aumento em 1 ponto percentual da taxa TEA-O eleva a renda em 1,88\% a um nível de significância de $5 \%$. No estágio 2 , um aumento de 1 ponto percentual da taxa TEA-O eleva a renda per capita em $0,26 \%$, porém a um nível de significância de $10 \%$. Todavia, no terceiro estágio do desenvolvimento a taxa TEA-O, exerce uma influência negativa na Renda per capita, no entanto não significativa. Corroborando com (ROCHA, 2014).

A taxa de empreendedorismo por necessidade TEA-N, revelou influência positiva não significativa para os países que se encontram no primeiro estágio do desenvolvimento. No entanto nos outros dois estágios do desenvolvimento as estimações denotam estar em conformidade com a teoria anteriormente exposta. Apresentando um efeito negativo e significativo sobre o PIB per capita. Observa-se que no estágio 2 um aumento em 1 ponto percentual taxa TEA-N reduz a renda per capita em $-0,17 \%$ a um nível de significância de 10\%. Já no estágio 3, um aumento em 1 ponto percentual taxa TEA-N reduz a renda per capita em $-0,14 \%$ a um nível de significância de $1 \%$. Corroborando com (ROCHA, 2014).

O índice global de competitividade $\mathrm{GCl}$ demonstra contribuir para o crescimento da renda per capita, apresentando um sinal positivo para os três estágios do desenvolvimento. Influenciando de forma mais expressiva o primeiro estágio do desenvolvimento, onde um aumento em 1 ponto percentual no índice $\mathrm{GCl}$ contribui para um aumento a renda per capita na ordem de 4,34\% a um nível de significância de 5\%. De forma análoga contribui para os estágios 2 e 3, no qual um aumento

\footnotetext{
${ }^{3}$ A comparação da atividade empreendedora de diferentes países diferentes ou dos mesmos países em diferentes períodos de tempo é o mesmo que comparar exércitos diferentes com base no número de soldados e não sobre a qualidade do arsenal. (ACS, 2009)
}

Estudos do CEPE [ISSN 1982-6729]. Santa Cruz do Sul, n. 45, p. 127-142, jan./jun. 2017. https://online.unisc.br/seer/index.php/cepe/index 
em 1 ponto percentual no índice $\mathrm{GCl}$ elevam a renda per capita em 1,0\% 1,58\%, a um nível de significância de $10 \%$ e $1 \%$ respectivamente. Os resultados corroboram com evidências de estudos anteriores (FONTENELE, 2011; ROCHA, 2014).

Os resultados apurados corroboram com a teoria anteriormente exposta. Países que se encontram na primeira fase do desenvolvimento, apresentam altas taxas do TEA em virtude das elevadas taxas de empreendedorismo por necessidade e auto emprego. Por sua vez no segundo estágio do desenvolvimento, com o setor industrial se desenvolvendo são geradas oportunidades de emprego reduzindo as elevadas taxas de auto emprego e empreendedorismo por necessidade, ocasionando uma redução na taxa TEA. Portanto nas primeiras fases do desenvolvimento é esperado que a taxa TEA influencie de maneira negativa o PIB per capita.

O terceiro estágio do desenvolvimento quando as economias estão amadurecidas com os pilares do desenvolvimento consolidados, é esperado que as taxas TEA reflitam o empreendedorismo inovador, baseado em percepção de oportunidades e na pesquisa e desenvolvimento P\&D, impactando de forma positiva no crescimento econômico, corroborando com o gráfico apresentado na Figura 3, que demonstra que a correlação entre TEA e PIB apresenta uma curva em forma de U.

\section{CONSIDERAÇÕES FINAIS}

O presente trabalho teve como objetivo analisar a relação entre atividade empreendedora e crescimento econômico no mundo. Este trabalho contribui com a literatura ao analisar esta relação com os países agrupados segundo sua fase de desenvolvimento, conforme apresentado no Relatório de Competitividade Global (GCR) e ao analisar esta relação sem a distinção de sua fase do desenvolvimento. Os resultados da pesquisa sugerem que a importância da contribuição dos empreendedores para o crescimento econômico varia de acordo com a fase de desenvolvimento em que o país se encontra, corroborando com a teoria.

Sugere-se, como pesquisa futura, a construção de um modelo mais amplo com a inserção de variáveis institucionais, bem com a utilização do Global Entrepreneurship Index (GEI), por meio de painel dinâmico pelo método econométrico System-GMM.

\section{REFERÊNCIAS}

ACEMOGLU, D.; JOHNSON, S.; ROBINSON, J. A. Institutions as a fundamental cause of long-run growth. Handbook of economic growth, v. 1, p. 385-472, 2005.

ACS, Z. J. et al. From entrepreneurship to economic development: Celebrating ten years of Global Entrepreneurship Monitor. Frontiers of Entrepreneurship Research, v. 29, n. 16, p. 1, 2009.

ACS, Z. J. et al. Global entrepreneurship monitor, 2004.

ACS, Z. How is entrepreneurship good for economic growth?. Innovations: Technology, Governance, Globalization, v. 1, n. 1, p. 97-107, 2006.

AFGHAH, S. M.; RAOOFI, A.; HOSHYAR, S. To Study the Effect of Entrepreneurship on Economic Growth, 2014.

Estudos do CEPE [ISSN 1982-6729]. Santa Cruz do Sul, n. 45, p. 127-142, jan./jun. 2017. https://online.unisc.br/seer/index.php/cepe/index 
ALMEIDA, F. M.; SEDIYAMA, G. S. S.; SANTIAGO, F. A. A Contribuição do Empreendedorismo para - Crescimento Econômico dos Estados Brasileiros. In: XIII Encontro Nacional da Associação Brasileira de Estudos Regionais e Urbanos, 2015, Curitiba - PR. ENABER 2015, 2015.

AUDRETSCH, D. B.; KEILBACH, M. C.; LEHMANN, E. E. Entrepreneurship and economic growth. Oxford University Press, 2006.

AUTIO, E. et al. Global entrepreneurship monitor 2007 executive report. Report, GERA, 2008.

BALTAGI, B. Econometric analysis of panel data. John Wiley \& Sons, 2008.

BARTOLOMEU, M. C. C. Crescimento económico, globalização e empreendedorismo: um estudo empírico. 2015.

BOSMA, N. et al. Global entrepreneurship monitor, executive report 2007. Babson Park, MA, London, UK: Babson College-London Business School, 2008.

BOSMA, N. et al. Global entrepreneurship monitor, executive report 2009. Babson Park, MA, London, UK: Babson College-London Business School, 2010.

DE CARVALHO ROCHA, E. L. Oportunidade ou necessidade? Um estudo do impacto do empreendedorismo no desenvolvimento econômico. Revista Gestão em Análise, v. 3, n. 1/2, p. 31-46, 2014.

DE OLIVEIRA, I. G. S.; CARDOSO, S. P. Empreendedorismo e suas implicações na inovação e desenvolvimento: Uma análise multivariada com indicadores socioeconômicos. Revista Globalização, Competitividade e Governabilidade, v. 9, n. 2, p. 43-60, maio-agosto 2015.

FONTENELE, R. E. S.; SOUZA, P. F. B.; LIMA, A. O. Empreendedorismo crescimento econômico e competividade dos BRICS: uma análise empírica a partir dos dados do GEM e GCl. Anais... Rio de Janeiro. ANPAD, 2011.

FONTENELE, R. E. S. Empreendedorismo, Competitividade e Crescimento Econômico: Evidências Empíricas/Entrepreneurship, Competitiveness and Economic Growth: Empirical Evidence. Revista de Administração Contemporânea, v. 14, n. 6, p. 1094, 2010.

HARPER, D. A. Foundations of entrepreneurship and economic development. Routledge, 2003.

MARQUES, R. G. O impacto do empreendedorismo no crescimento económico: um estudo empírico para os países da OCDE. 2014. 74 f. Tese (Mestrado em Economia) - Faculdade de Economia, Universidade do Porto, Porto. 2014.

MRABET, A.; ELLOUZE, A. Entrepreneurship and economic growth: meta-analysis. Impact Journals, v. 2, n. 5, p. 57-72, 2014.

SALA-I-MARTÍN, X. et al. Reaching Beyond the New Normal: Findings from the Global Competitiveness Index 2015-2016. The Global Competitiveness Report 2015-2016, 2015.

SCHWAB, KI.; SALA-I-MARTíN, X. World Economic Forum's Global Competitiveness Report 20142015. World Economic Forum, 2015.

SMITH, D. The role of entrepreneurship in economic growth. Undergraduate Economic Review, v. 6, n. 1, p. 7, 2010.

STAM, E.; VAN STEL, A. Types of entrepreneurship and economic growth. Entrepreneurship, innovation, and economic development, p. 78-95, 2011.

VAN STEL, A. J.; CARREE, M. A.; THURIK, A. R. The effect of entrepreneurship on national economic growth: An analysis using the GEM database. Papers on entrepreneurship, growth and public policy, 2004.

Estudos do CEPE [ISSN 1982-6729]. Santa Cruz do Sul, n. 45, p. 127-142, jan./jun. 2017. https://online.unisc.br/seer/index.php/cepe/index 
WONG, P. K.; HO, Y. P.; AUTIO, E. Entrepreneurship, innovation and economic growth: Evidence from GEM data. Small Business Economics, v. 24, n. 3, p. 335-350, 2005.

Estudos do CEPE [ISSN 1982-6729]. Santa Cruz do Sul, n. 45, p. 127-142, jan./jun. 2017. https://online.unisc.br/seer/index.php/cepe/index 